\title{
A Tomb with a View: Axonometry in Early Chinese Cartography
}

In a series of lectures on the revolution of modern science that he gave at the University of St. Andrews in 1955, Werner Heisenberg, the German Nobel Prize quantum physicist, lucidly explained the Copenhagen Interpretation of Quantum Physics ${ }^{1}$ and emphasized that "we have to remember that what we observe is not nature herself, but nature exposed to our method of questioning." Heisenberg's lectures were subsequently published in Physics and Philosophy: The Revolution in Modern Science, which has since become a seminal text of modern thought for his applications of quantum physics theory to social sciences and humanities. In 2016, at a conference on art and visuality in the global age, contemporary art historian and critic Celeste Ianniciello invoked Heisenberg and further suggested that, sixty years later, Physics and Philosophy continues to have a profound impact on our perceptions of the modern world.

Quantum physics conceives reality as an unlocatable energy made of particles and waves which acquire form through a performative act of measurement. Matter is generated by this differential act, where the observer and the observed are inseparable and part of the world in its differential becoming. Matter then emerges through an act of contamination, migration, border-crossing. Difference is the process of mattering in which the world articulates itself differently. ${ }^{3}$

1 Jan Faye, “Copenhagen Interpretation of Quantum Mechanics”, in Edward N. Zalta, ed., The Stanford Encyclopedia of Philosophy (Stanford: Stanford University Press, 2014). https://plato. stanford.edu/archives/fall2014/entries/qm-copenhagen/. "The Copenhagen interpretation was the first general attempt to understand the world of atoms as this is represented by quantum mechanics. The founding father was mainly the Danish physicist Niels Bohr, but also Werner Heisenberg, Max Born and other physicists made important contributions to the overall understanding of the atomic world that is associated with the name of the capital of Denmark." Also see Hermann Wimmel, Quantum Physics \& Observed Reality: A Critical Interpretation of Quantum Mechanics (Singapore: World Scientific Publishing Pte. Ltd., 1992), 2-3.

2 Werner Heisenberg, Physics and Philosophy: The Revolution in Modern Science (New York: Harper and Brothers, 1958), 38. "This again emphasizes a subjective element in the description of atomic events, since the measuring device has been constructed by the observer, and we have to remember that what we observe is not nature in itself but nature exposed to our method of questioning."

3 Celeste Ianniciello, "Postcolonial Art: A Living Archive of Border-Crossings and Migrant Matters,” in Anna Maria Guasch Ferrer, Nasheli Jimenez Del Val, eds., Critical Cartography of Art

Ә Open Access. ( 2022 H. M. Agnes Hsu-Tang, published by De Gruyter. (c) BY-NC-ND This work is licensed under the Creative Commons Attribution-NonCommercial-NoDerivatives 4.0 International License. 


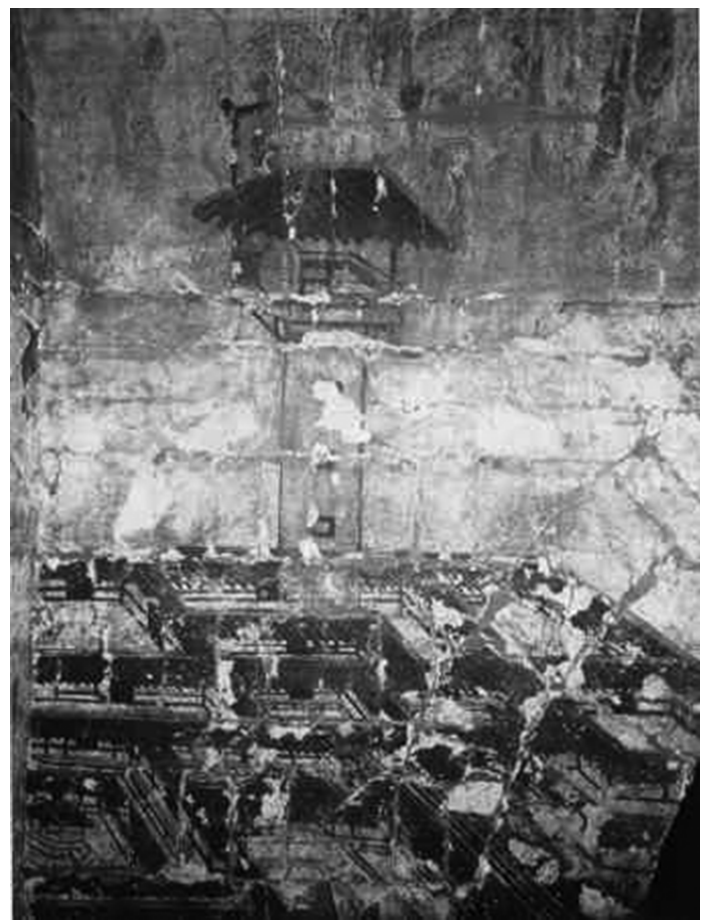

Figure 1: Main section of the "townscape" mural found inside the Anping tomb; architectural features shown include a multi-story drum tower, siheyuan 四合院 quadrangles, and a defensive wall. Photo by author of a purported replica, 2001.

In this study of a second-century CE polychromatic monumental wall painting of a town found in an Eastern Han dynasty (25-220 CE) tomb (Figure 1), I begin with Heisenberg's principle to present a disaggregate approach based on postprocessual archaeology, semantics, behavioral geography, modern architectural criticism, and Foucauldian discourse analysis. This unorthodox method of inquiry builds on a corpus of textual and visual studies on extant Early Chinese representations of geography. Earlier analyses were groundbreaking in their times; however, it has become necessary to propose a new paradigm to study ancient Chinese cartography as newly excavated evidence has come to light.

I have presented earlier iterations of this study to specialists in cartography, art history, and archaeology; the current inquiry is my response to the

and Visuality in the Global Age (Newcastle upon Tyne: Cambridge Scholars Publishing, 2014), 19-34, 31. 
valuable and considered feedbacks offered by many generous colleagues. In 2008, I proposed that the significance of this ancient depiction of a place can only be fully understood in an emic context, i.e., a conscious viewing of the image from the eyes of the actors that produced and used the image within the culture to which they belonged, as opposed to from a cross-cultural, crosstemporal etic perspective. ${ }^{4}$ In the emic context, however, this image found on the wall of an ancient tomb does not fit neatly into the rubrics that cartographic historians would apply to a traditional map, which Christian Jacob has defined as a concrete or monumental map, “deriving from a particular mimetic process in which the landscape is miniaturized, as a metonymic double of reality. In their primitive form, as in their technical avatars, they attest to a particular vocation of the map, in which are mixed a Gulliverian dream and belief in the effectiveness of sympathetic magic." 5 When I first proposed to treat this image as a "map", I knew what type of map this was not, but I did not know what it was. That was the impetus to continue to look for a different theoretical approach beyond Sinology, art history, and archaeology.

According to Ptolemy's classification that draws a distinction between geography, which are maps of the known world, and chorography, which are depictions of khoros $\chi \tilde{\omega} \rho{ }^{\prime}$ (place), this ancient Chinese pictorial representation is characteristically chorographic. Chorography is further defined in a 2013 study on medieval mapmaking in the Western world, in which Jesse Simon traces the etymological origins of chorography in the Ptolemaic tradition and explains:

The first part of the word, however, presents us with something of a grey area: $\chi \underline{\omega} \rho \alpha$ often refers to land or country in an indefinite, non-political sense, while $\chi \tilde{\omega} \rho \circ$ is neither as spe-

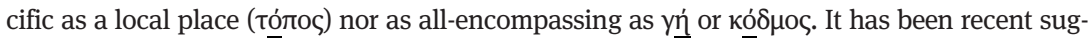
gested that $\chi \tilde{\omega}$ poৎ may be understood in a similar way to the modern concept of 'landscape', that is, an area of land that can be apprehended and experienced by an observer. The defin-

4 An early version of this study was published in Hsin-Mei Agnes Hsu, "Structured Perceptions of Real and Imagined Landscapes in Early China," in Kurt A. Raaflaub and Richard J. A. Talbert, eds., Geography and Ethnography: Perceptions of the World in Pre-Modern Societies (Oxford: Wiley-Blackwell, 2010), 43-63. A revised version was presented on a panel on cartography at the European Association of Chinese Studies Annual Conference organized by Vera Lichtman and Hilde De Weerdt in 2012.

5 Christian Jacob, The Sovereign Map: Theoretical Approaches in Cartography throughout History, Tom Conley, ed. and Edward E. Dahl, trans. (Chicago: University of Chicago Press, 2006), 39. 
ing characteristic of $\chi \tilde{\omega}$ pos, however, seems to be its limits. The word appears most often in classical sources to describe a space which is finite and bounded, land which need not necessarily be perceived in a single glance, but whose extent is nonetheless known. ${ }^{6}$

This classification is not unique to early Chinese maps, as many transmitted and excavated maps from other early cultures were also localized depictions of the mapmakers' perceived world. ${ }^{7}$

Formal analysis of this ancient chorograph shows a bird's-eye view of a town consisted of public structures, private spaces, pathways, and fortifications; for this reason I refer to this image as a "townscape" in the present study. I will demonstrate that while the place depicted was modeled after contemporary urban centers, it was most likely located in a rural region in the Northern frontiers of Han territories. At least six other examples of townscapes dating to Early China have been excavated and published, ${ }^{8}$ but I will show that this particular representation is unique when studied against the other examples and in the context of this tomb's pictorial program. In this case, artistic intention may have been ancillary to an imagined functionality, aptly described by modern architectural critics and contemporary urban designers as "imageability."

Graphic representations of geography in the form of maps reflect a set of structured human perceptions specific to a culture and a time in history. A landscape as a natural phenomenon is devoid of preconceptions associated with artificial definitions; however, when a landscape is perceived and demarcated by its human possessor, it becomes ideologically significant. It can be said that the meanings of a map are processed as symbols and embedded intrinsically in a representational format. The relationship between symbol and object - in particular, the ideological purposes of landscape as represented in maps - has been explored by scholars across disciplines. Alfred Korzybski, widely recognized as the father of general semantics, offered an observation on this philosophical quandary in the 1930s: "A map is not the territory it represents, but, if correct, it has a similar structure to the territory, which accounts for its usefulness." ${ }^{9}$ In other words, maps as a mode of

6 Jesse Simon, "Chorography reconsidered: An alternative approach to the Ptolemaic definition,” in Keith D. Lilley, ed., Mapping Medieval Geographies: Geographical Encounters in the Latin West and Beyond, 300-1600 (Cambridge: Cambridge University Press, 2013), 23-44.

7 Lloyd Brown, The Story of Maps (Boston: Little, Brown, and Co., 1949), 33.

8 Anneliese Bulling, "The Eastern Han Tomb at Ho-lin-ko-erh (Holingol)," Archives of Asian Art 31 (1977-8), 79-103.

9 Alfred Korzybski, Science and Sanity: An Introduction to Non-Aristotelian Systems and General Semantics (New York: International Non-Aristotelian Library Publishing Company, 1933), 747-61. 
communication manifest meanings only when the observed (i.e., "nature herself exposed") is interpreted by the observer (i.e., "our method of questioning”). Heisenberg's principle helps us recognize that the etic method of interpretation is intrinsically biased because it presumes a common worldview between the ancient mapmaker in second-century China and the modern interpreter of the map in twenty-first century America. It is also important to remember that the "place" depicted in this image, sealed inside a tomb for almost two millennia, remains unchanged because it was "frozen in time" until its modern discovery, even though the actual structures and landscapes no longer exist. This image therefore ceased to be a practical illustration of the physical world at the time of the tomb owner's death. In the postmortem context, the "place" is a cognitive mimesis of a lost reality that is unique to the deceased, not to the modern researcher. This image became a mental map.

Mental maps were first known as "cognitive maps" in the early works of behavioral geographers whose approach to geography focused on the cognitive processes underlying spatial reasoning, decision-making, and behavior. A seminal work on mental maps is The Image of the City, published in 1960 by the noted American urban planner Kevin Lynch, a former student of Frank Lloyd Wright. Lynch went on to a distinguished 30-year academic career at the Massachusetts Institute of Technology. In The Image of the City, Lynch invented two concepts that have become standard semantic tools in modern architectural criticism, "imageability" and "wayfinding," both of which are applicable and valuable to our understanding of this early Chinese chorograph. Imageability is defined as a "character or quality held by a physical object" that triggers lucid images in the observer. Wayfinding is the employment of mechanisms that literally "guide the way." Lynch further posited that "we have the opportunity of forming our new city world into an imaginable landscape: visible, coherent, and clear. It will require a new attitude on the part of the city dweller, and a physical reshaping of his domain into forms which entrance the eye, which organize themselves from level to level in time and space, which can stand as symbols for urban life." ${ }^{10}$ In the subsequent decade, writings by historian of geography David Stea were influential in the developing field of study of "mental mapping." 11 Fellow geography historian Elspeth Graham summarizes Stea's view as “an image resulting from the filtering and coding of sensory data and is somewhat subjective, private, unique."12

10 Kevin Lynch, The Image of the City (Cambridge: The MIT Press, 1960), 91.

11 Roger Downs and Dr. David Stea, Maps in Minds: Reflections on Cognitive Mapping, Harper \& Row series in geography (New York: Joanna Cotler Books, 1977).

12 Elspeth Graham, "What is a Mental Map?" The Royal Geographical Society (with the Institute of British Geographers) v. 8, n. 4 (1976), 259-262, referring to D. C. D. Pocock, "City of 
An intrinsic element in the study of mental mapping is the concept of domain, which was explored in depth by the French philosopher Michel Foucault. Foucault was not a historian of geography or a mapmaker, but he challenged the traditional academic study of cartography to demonstrate the power-knowledge concept inherent in the process of making and using maps in a 1976 interview with the French geography journal Hérodote.

Territory is no doubt a geographical notion, but it's first of all a juridico-political one: the area controlled by a certain kind of power. Field is an economico-juridical notion. Displacement: what displaces itself is an army, a squadron, a population. Domain is a juridicopolitical notion. Soil is a historico-geological notion. Region is a fiscal, administrative, military notion. Horizon is a pictorial, but also a strategic notion. ${ }^{13}$

Foucault's discourse analysis was particularly influential in the scholarship of the renowned British historical geographer J. B. Harley, who with David Woodward co-edited the first three volumes of the important History of Cartography Project until his untimely passing in 1991. In his 1989 article in Cartographica, Harley summarized the paradigm shift from the historical study of maps as devices of communication of geography to the poststructuralist approach of treating maps as socio-political constructs. "From Foucault's writings, the key revelation has been the omnipresence of power in all knowledge, even though that power is invisible or implied, including the particular knowledge encoded in maps and atlases."14

The issue of domain has not been fully explored in Early Chinese cartography, even though numerous references to maps and mapmaking are found in extant texts from this period. Two notable examples in Sima Qian's 司馬遷 Shiji (Records of the Historian 史記) associated with the Progenitor Emperor of China are especially enlightening. One is the story of Jing Ke's 荊軻 failed attempt to assassinate the King of Qin. This legend has become an indelible part of the Chinese psyche that even primary school children today can recite the story. In 2008, an ahistorical version of the story was made into an international blockbuster film aptly titled "Hero." A gist of the story is as follows: in order to obtain an audience with the King of Qin, an assassin named Jing Ke pretends to be an aristocrat-envoy from a rival kingdom offering two precious

the Mind: A Review of Mental maps of Urban Areas," Scottish Geographic Magazine 88 (1972), 2, 115.

13 Michel Foucault, “Questions on Geography?” in Colin Gordon, ed. and trans., Power/Knowledge: Selected Interviews and Other Writings, 1972-1977 (New York: Pantheon, 1980), 63-77, 68.

14 J. B. Harley, “Deconstructing the Map,” Cartographica, v. 26, n. 2 (Spring 1989), 1-20. 
gifts - a map of the territories that his lord would surrender and the head of a former Qin general, who had lost favor with the King of Qin (the general had virtuously sacrificed himself for this regicidal-suicidal mission). During his audience with the king, Jing Ke slowly unrolls the map until, suddenly, a (poisoned) dagger is revealed. Jing Ke deftly grabs the dagger and lunges at the king, but he misses. A madcap chase around a column ensues, and the royal physician valiantly throws his medicine bag at Jing Ke, allowing the king time to react. The king then draws his ceremonial sword and injuries Jing Ke, who in a desperate final attempt throws his dagger at the king, but misses again. The king stabs Jing Ke multiple times before the royal guards arrive and kill Jing Ke and his assistant. Shortly after Jing Ke's failed assassination attempt, the King of Qin completes his conquest and unifies all under heaven to become the selfstyled Progenitor Emperor of China.

In another anecdote from the Progenitor Emperor's biography in Shiji, Sima Qian describes the emperor's purposeful creation of a three-dimensional map of the cosmic and terrestrial worlds inside his imperial tomb:

穿三泉, 下銅而致槨, 宮觀百官奇器珍怪徙蔵滿之。令匠作機姱矢, 有所穿近者輙射之。以 水銀為百川江河大海, 機相灌輸, 上具天文, 下具地理。(史记. 卷六. 秦始皇本纪)

They dug through three subterranean streams and poured molten copper for the outer coffin, and the tomb was fitted with models of palaces, pavilions and offices, as well as fine vessels, precious stones and rarities. Artisans were ordered to fix up crossbows so that any thief breaking in would be shot. All the country's streams, the Yellow River and the Yangtze were reproduced in quicksilver and by some mechanical means made to flow into a miniature ocean. The heavenly constellations were shown above and the regions of the earth below. ${ }^{15}$

These stories illustrate that maps were more than practical tools for administration in Early China; they were symbols of conquest and sovereignty. In life, and before the completion of his conquest of the warring kingdoms, there was no gift more enticing to the King of Qin than a pretty picture of the lands and peoples that he is about subdue. In eternity and as the Progenitor Emperor of a unified China, he believed that he would continue to command "all under heaven" by being entombed inside a simulated microcosm of his domain.

It is only in the last forty years that pictorial depictions of domain from Early China have come to light through archaeological discoveries. These excavated materials predate the accepted formal origin of the Chinese landscape painting tradition in the Northern and Southern dynasties (220-589 CE); for

15 Edmund Capon, Qin Shihuang: Terracotta Warriors and Horses (Clayton, Victoria, Australia: Wilke and Company Limited, 1983), 24. 
this reason, previous attempts to study them from an anachronistic perspective have proven unsatisfactory - for while every domain is a landscape, not every landscape is a domain. Etymologically, the common Classical Latin verb domare denotes "to subdue."16 Domain, therefore, connotes a conquered and controlled landscape by a human possessor. Archaeological evidence indicates that the practice of including maps as funerary accoutrements in Early China can be traced back to the Warring States period (c. 475-221 BCE). A set of seven fragmented maps on wooden planks - comparable to the ancient Greek concept of pinax ${ }^{17}$ riv $\alpha \xi$ - discovered in a tomb at Fangmatan in modern Gansu province are some of the earliest known examples of cartography in Chinese history; they have been dated to 239 BCE and depict the hydrology of the Wei River valley and its tributaries. ${ }^{18}$ A set of topographic and garrison maps, dated to 168 BCE and recovered from Mawangdui tomb number three in Hunan province, further illustrates that the practice of making concrete maps was highly developed by the time of the early Western Han (202 BCE-9 CE). ${ }^{19}$

The townscape in our current inquiry postdates the concrete maps found at Fangmatan and Mawangdui. This image was discovered to have been painted on a wall inside a grand tomb in Anping 安平 county in modern southern Hebei province. The tomb is an impressive subterranean structure built to replicate a contemporary grand estate of multiple chambers. The interior walls were decorated with an extensive collection of polychromatic murals painted in mineralbased colors over dry plaster using an organic binding mixture. An inscription found in situ, 惟喜平五年 (fifth year of the Xiping Era), gives the terminus ante quem of 176 CE during the Eastern Han dynasty (25-220 CE).

This image was found on the western part of the northern wall in an ancillary chamber. All painted fragments and artifacts salvaged from the tomb were removed from the tomb after initial excavations in the early 1970s; it is believed

16 Domare is common in Classical Latin, which also offers with similar meaning domari. Also see George D. Chase, “The Form of Nominal Compound in Latin,” Harvard Studies in Classical Philology, v. 11 (1900), 61-72.

17 Jacob, “The Sovereign Maps," 18. "In Ancient Greek, the term map is generally known as pinax, indicating the tablet (of wood, metal, or stone), then the 'plate' (in the bibliographical sense, meaning thus a 'plate' of papyrus or of parchment) on which forms are drawn, painted, or engraved. A pinax can present to the eye an alphabetical inscription (a text or list), geometrical figures, or figurative drawings or paintings."

18 Cordell Yee, "Reinterpreting Chinese Geographical Maps," in J.B. Harley and David Woodward, eds., The History of Cartography Project, Volume 2, Book 2 (Chicago: University of Chicago Press, 1994), 35-70.

19 Hsin-Mei Agnes Hsu and Ann Martin-Montgomery, “An Emic Perspective of the Mapmaker's Art in Han China," Journal of the Royal Asiatic Society, ser. 3, v.17, n. 4 (October, 2007), 443-457. 
that they were then transported to and have since remained in a storage facility at the Hebei Provincial Museum. My repeated requests to study the original fragments were never fulfilled; my understanding has been that only replicas are available for study and exhibitions. I have visited the site where the tomb was discovered, but only a modern landmark stands in situ.

According to the excavation report, the baseline of the townscape is set at $20 \mathrm{~cm}$ above ground; the painting itself is $230 \mathrm{~cm}$ long and $135 \mathrm{~cm}$ wide, and occupies two-thirds of the entire northern wall. Chinese scholars had proposed that the architectural plan is shown to have a southern exposure "in light of China's architectural tradition of 'sitting in the north and facing the south,' the upper part of the painting should be the north." ${ }^{20}$ If we accept this interpretation, then the mural shows the southern, northern, and eastern parts of the town; the western part is only partially depicted. As for the method of representation, it has been suggested that the artist intentionally used the partial-view technique to demonstrate the town's expanse. ${ }^{21}$ This presentation adheres to Jacob's theory that "the ephemeral (mental) map can be selective and partial, for it is focused on its illustrative function or on its functions as a point of reference determined by the immediate context of its drawing."22 We will return to this point later.

Formal analysis indicates that rulers and T-squares were used to form clean outlines of the architectural elements in the painting. Illusion of depth and volume is created by the varying use of thick and thin lines. Doors, windows, and roofs are all painted in black. Corridors and some ridgepoles are painted in green. Other elements are painted in brown and almost invisible to the naked eye after two millennia of natural deterioration. Vermillion paint is used only to depict the drum and the pennant. This visual aide effectively articulates the prominence of these two features and their iconographic significance.

Buildings of various sizes, all arranged in the enclosure style (siheyuan 四合院), form the perimeter of the compound. There is an outer layer of walls; for this reason the layout resembles the Chinese graph hui 回, which is best described as a small square enclosed in a large square. The interior is further divided into smaller units of enclosed quadrangles, which seem to comprise a series of common spaces and residential areas connected by meandering pathways and covered corridors. The only entrance to this town is a set of double gates situated in the center of the southern perimeter. The outer gate is covered

20 Hebeisheng Wenwu Yanjiusuo, Anping Dong Han bihua mu (Beijing: Wenwu chuban she, 1990), 28.

21 Ibid.

22 Jacob, "The Sovereign Maps," 33. 
with a roof of overhanging eaves. The inner gate is structurally similar to the outer one. The roofs of both gates are taller than the roofs of all other buildings. The inner gate opens into a large courtyard. At the northern end is a spacious hall situated on the east-west axis; this hall seems to be the nucleus of the town in the context of the overall layout. Two covered parallel corridors flank the courtyard and the audience hall to provide sheltered passage between the entrance in the southernmost part of the compound and its inner sanctum.

In his study on Chinese vernacular architecture Ronald Knapp observes that the origin of the enclosure style can be traced back to Early China and that it was already a common architectural element by the Eastern Han times.

The overall composition of the siheyuan, a residential quadrangle, involves an orientation toward the south, clear axiality and balanced side-to-side symmetry. In both figures, the central courtyard and associated open spaces are generous portions of the overall dwelling, representing as much as 40 percent of the total area. Indeed, the principal courtyard is often larger than any of the structure which together makes up the house. These structures surrounding the courtyard are single-story units with narrow verandas, providing a covered circuit for movement about the complex. Symmetrical placement of trees, walkways, and gateways complements the balanced proportions of the siheyuan itself. Seclusion is ensured by the surrounding walls and gates. Yet from any position in the courtyard of these northern dwelling complexes, the sky appears to reach to distant horizons unobstructed either by the dwelling itself or by neighboring buildings. Larger siheyuan complexes, created by the addition of more rooms and courtyards, maintain the overall links between the encompassed earth and expanding sky. ${ }^{23}$

The Anping townscape is made up of enclosures of various sizes. The main courtyard is larger than all the buildings, including the central audience hall. Movement on foot, or wayfinding, within the compound would have been easy along the undulating but well-organized covered pathways. The layout is complex but conveys a sense of symmetry.

A tower on the northern perimeter and a freestanding structure inside a courtyard in the western part of the town are two structures that stand out. The latter is a small building with a southern exposure that sits on a platform with steps providing access to an elevated area. The structure is covered with a roof and its ridgepole has stylized owl-tail tips. Some have suggested that this structure is a pavilion. ${ }^{24}$

The tower consists of a tall platform and an open-air building; it is an impressive, but likely exaggerated or imagined, five-story structure. Rising above

23 Ronald G. Knapp, China's Vernacular Architecture: House Form and Culture (Honolulu, University of Hawaii Press, 1989), 38.

24 Hebeisheng Wenwu Yanjiusuo, “Anping Dong Han bihua mu,” 28. 
the roof of the tower is a short black pole, to which a pennant in the shape of a long bird-tail, painted in vermillion, is affixed. There are railings all around the open-air building, inside of which is a large red drum; traces of vermilion are still visible. Some scholars have called this edifice a watchtower (wanglou), ${ }^{25}$ although it would not be inaccurate to call it a drum tower (gulou). Nancy Steinhardt's study on these towers and their functions confirm the possible dual purpose of this architectural form in the Anping townscape:

Another feature of Chinese imperial city outer walls was the defensive projection, which took the form of a lookout tower or a protective battlement. Lookout towers were built at the four corners of a city and atop city gates, where troops could be quartered. ${ }^{26}$

The last structure planned inside the walls of the Chinese imperial city was the freestanding tower. One and often two types of the multistoried structures stood on the main north-south axis of imperial Beijing and certain earlier Chinese capitals. The towers housed either a bell or a drum, and their functions were those of urban timekeeping devices. The bell or drum was sounded at regular intervals during the day and night. ${ }^{27}$

In the Anping townscape, the combination of the tower's strategic location on the northern perimeter, height, and crenellations indicate that its primary functions were observation and defense. The large drum in the watchtower could be used for marking time and sounding alarm - for internal emergencies and for when the town was threatened by an invasion. A logical explanation of the tower's dual function is that the Anping painting does not portray a typical Eastern Han city, but a frontier town built to resemble a contemporary city. In other words, the Anping mural depicts rural architecture infused with contemporary urban features.

The distinction between urban and rural Chinese architecture has been a topic of much scholarly debate, most notably between Frederick Mote and William Skinner. Skinner contested Mote's proposition that "Chinese urban structures were indistinguishable from rural structures," 28 and argued that Chinese urban structures were noticeably different from rural structures in pre-modern times. "On the more prosaic level of architectural forms, Chinese cities did have their distinctive edifices: the drum tower and bell tower, the great examination hall, and the elaborate towers at the corners and gates of the city wall." ${ }^{29}$ In a

25 Ibid.

26 Nancy S. Steinhardt, Chinese Imperial City Planning (Honolulu: University of Hawaii Press, 1990), 7.

27 Steinhardt, “Chinese Imperial City Planning," 16-18.

28 Frederic W. Mote, “The Transformation of Nanking, 1350-1400,” in G. William Skinner, ed., The City in Late Imperial China (Stanford: Stanford University Press, 1977), 115-6.

29 G. William Skinner, "Introduction: Urban Development in Imperial China," in G. William Skinner, ed., The City in Late Imperial China (Stanford: Stanford University Press, 1977), 16-7. 
later study on urban-planning in pre-modern China, Xu Yinong re-examined Skinner's theory and approached the study of urban architecture from the perspective that city walls had always been the fundamental feature of pre-modern city planning. ${ }^{30}$

I have insisted that, in terms of architectural form and style, buildings in a traditional Chinese city can hardly be differentiated from buildings in its surrounding countryside. Structures that appear to be distinctively "urban," such as the city gate towers, the corner towers, the drum tower, and bell tower, were in fact a combination of one or two-story halls with the city walls or high raised, wall-like platforms on which the halls stood. The architectural form and style of these halls were not at all distinguishable from those on the ground; it was the city wall and wall-like platforms that rendered these particular "urban structures," in many cases (but not always), distinct from rural buildings. ${ }^{31}$

It is my analysis that the Anping mural depicts a place far away from the capital on the northern border of the Han empire. The absence of any form of vegetation, wells, and a moat indicates that the town is situated in a barren region of Chinese-controlled territories. The most convincing piece of evidence, however, is the town's layout. Zhou Changshan, a prominent Chinese urban historian whose groundbreaking scholarship includes the most credible calculation of the size of wards in Chang'an in the Western Han period, has asserted that Han cities in the northern border region were almost always built in the hui configuration with only one entrance in the center of the southern perimeter. Excavations at the ruins of an ancient frontier city at Huhehaotetatu in Inner Mongolia confirm this observation. ${ }^{32}$ Zhou explains that this architectural configuration reflects the terrain of the northern region and the defensive nature of these frontier towns. The absence of a moat, which was a common defensive feature of cities in the Central Plain region, is indicative of the aridity of the northern border region. Further, because towns in the border regions were built as defensive fortresses against nomadic invaders from the north, any openings along the northern perimeter would have been strategically vulnerable. ${ }^{33}$

A key feature of the Anping townscape is the artist's use of axonometric perspective, more commonly known as the parallel perspective. In computer graphic terminology, this method of projection is in fact called the "Chinese perspective" because of the widespread belief that the practice had developed

$30 \mathrm{Xu}$ Yinong, The Chinese City in Space and Time: The Development of Urban Form in Suzhou (Honolulu: University of Hawaii Press, 2000), 175.

$31 \mathrm{Xu}$, "The Chinese City in Space and Time," 43.

32 Zhou Changshan, Handai chenshi yanjiu (Beijing: Renmin chubanshe, 2001), 61.

33 Zhou, "Handai chenshi yanjiu," 43. 
from the Chinese scroll painting tradition. ${ }^{34}$ Axonometric perspective differs from the linear perspective, which is based on Euclidian optics, in that it has no explicit vanishing points, and in many cases, no explicit source of light. In a painting drawn from the axonometric perspective, objects farther away from the viewer are not smaller than those that are closer to the viewer. Thus, if information of the scale and properties of the projection in an axonometric drawing are provided, one can determine the size of any object in the drawing; this is also the reason that architects use axonometry in their concept renderings. In the words of architectural historian Bernard Schneider, "perspective shows what we see of an object, whilst axonometry shows what we know about it."35 The horizon in an axonometric drawing is set above the painting, thus giving "many Chinese pictures the character of bird's-eye views." 36

Joseph Needham clearly believed that the use of axonometric perspective could be traced back to as early as the Han times. ${ }^{37}$ "Parallel perspective can be found already in the drawing of the scenes carved in relief in the stone tomb shrines of the Han period (Chu Wei, Wu Liang, etc.). Diagonal lines strike off from the front line of the picture, with figures or buildings along them." 38 Architectural plans shown in bas-relief and intaglio from the Han period, particularly those found in the Shandong province, such as the $\mathrm{Wu}$ Liang shrine and the Yinan tomb, have been examined in detailed studies by $\mathrm{Wu}$ Hung and Lydia Thompson. In a 2001 study, James Coswell further proposed an alternative term to describe the pre-modern Chinese way of viewing, which he called "situational perspective." He described a second-century CE depiction of a market scene on an impressed tile found in a tomb in Sichuan as follows:

The disparate angles do at least two things. First they capture the hurly-burly of the market itself with lines leaning this way and that. Second, in a subtle but sophisticated way I believe they convey the sense of actually moving through the market where the visitor's vantage point changes with every step. In other words, there is no attempt in this tile to describe a unitary space or a single movement. In this regard it is important to note that all of the figures are of the same size, so even the mechanism of recession in size the farther an object is from the viewer is not used. The end result is of on-going activities, perhaps

34 J. Krikke, “Axonometry: A Matter of Perspective," IEEE Computer Graphics and Applications (2000), 7-11.

35 Anna, Norbert Miller, Werner Oechslin and Bernhard Schneider, eds., "Zeichnung als Medium der Abstraktion/Drawing as a Medium of Abstraction,” DAIDALOS (1981), 81.

36 Joseph Needham, Science and Civilization in China, IV (Cambridge: Cambridge University Press, 1971), 112.

37 Ibid., fig. 776.

38 Needham, Science and Civilization in China, 114. 
even in an eternal sense, which would be appropriate, for this picture was meant to accompany the deceased of the tomb where this tile was found into the hereafter where neither space nor time mattered." 39

Painted directly across from the townscape in the Anping tomb is a rotund man shown seated on a dais under a canopy, attended by servants. He is literally "larger than life" as he is depicted three times larger than all other human figures in this tomb; he is also the only one shown in a frontal view. There is little doubt that this is a representation of the owner of this chthonic mansion. His bulbous eyes are wide open. His right hand is depicted as if he is beckoning the mourner. His dignified seated pose, ensemble, and accoutrements, are all manifestations of his moral character and his status as the tomb owner. ${ }^{40}$ There are earlier images of deceased persons in Chinese art, but this painting is the earliest known example of a frontal, seated portraiture - a style that would become the standard form of portraiture in Chinese art for the next two millennia. In this painting, the tomb owner's gesture and pose are particularly significant when interpreted in the context of the pictorial program. The fact that the city is drawn from an axonometric perspective gives a sense that the tomb owner is looking down at it from a vantage point far above. The tomb's pictorial program was designed to illustrate the power dynamic between the man and the townscape, and that the townscape was, and remains in the post-mortem perpetuity, his domain.

Architectural murals have also been excavated from other tombs with evident Eastern Han characteristics, but the Anping townscape is unique among them. Six murals were found in a tomb at Helinge'er in modern Inner Mongolia; three were studied in depth by Anneliese Bulling in her meticulous account published in the late 1970s, in which she observed: "Houses are drawn in different perspectives, some showing only the roofs as if seen from above, others showing a building as seen from the front." Further studies of two of the murals, the so-called Ningcheng and Fanyangcheng townscapes, confirm that they, too, were drawn from an axonometric perspective.

In the Helinge'er tomb, the so-called Ningcheng architectural mural would have been the first of the six that a mourner encountered as it is positioned on the northern wall of the corridor connecting the antechamber and the central

39 James O. Caswell, "Some 'Secrets of the Trade' in Chinese Painters' Use of 'Perspectives', RES: Anthropology and Aesthetics, n. 40 (Autumn, 2001), 188-210.

40 Audrey G. Spiro, Contemplating the Ancients: Aesthetic and Social Issues in Early Chinese Portraiture (Berkeley: University of California Press, 1990), 14. 
chamber. ${ }^{41}$ Bulling speculated that this mural was the most important among the six because "this was the place where the Master of the Tomb was stationed at the time when he had reached his highest position as a $\mathrm{Hu}$ Wu-huan hsiaowei, Colonel Protector of the Wu-huan." 42 Wen Fong also examined this painting and commented that:

A series of courtyard scenes created by parallelograms presents a bird's-eye view of enclosed spaces filled with rows of figures and buildings. Parallelograms also form the edges of a floor mat and the sides of a building to position the figures in space. As with the diagonal lines of the gabled-roof motif of the Helingol wall painting, overlapping triangular mountain motifs are used to form parallelograms to suggest spatial recession in landscape representation. ${ }^{43}$

While the Helinge'er murals are important to our formal analysis of the Anping painting, they differ in one critical aspect in that the Anping townscape is completely devoid of human presence. In contrast, all six Helinge'er murals show robust human activities and the hustling and bustling of town life, leading Steinhardt to comment that "indeed, one observes more varied activity on the painted wall than in the main intersection of Ningcheng today!"44

In Western art, the parallel perspective was the historically preferred method of representing space. It was an "alternative to the optical 'deceptions' of pictorial perspective" for achieving "precision in technical illustration." 45 The most notable works in this field of study were produced by Johann Heinrich Lambert, a Prussian military scientist, and Reverend William Farish, an English mathematician and engineer. Lambert was initially known for his work on military cartography that led him to become a pioneer in the study of non-Euclidian concepts. ${ }^{46}$ His study on parallel projection resulted in the insight that it "became increasingly used to convey information," so that it was called the "military perspective." 47 Farish also championed the value of descriptive geometry in precision drawings; he called it “isometrical perspective." Development of the axonometric perspective in Western art suggests that this method of projection was not widely used for artistic enhancement but, because it shows descriptive geometry in precise terms, was most

41 Neimenggu Wenwu Gongzuodui and Neimenggu Bowuguan, "Helinge'er faxian yizuo zhongyao de Dong Han bihua mu," Kaogu 1 (1974), 11.

42 Bulling, "The Eastern Han Tomb at Ho-lin-ko-erh”, 83.

43 Wen Fong, "Why Chinese Painting is History," Art Bulletin 85.2 (2003), 273.

44 Steinhardt, "Representations of Chinese Walled Cities in the Pictorial and Graphic Arts”, 428.

45 Martin Kemp, The Science of Art: Optical Themes in Western Art from Brunelleschi to Seurat (New Haven: Yale University Press, 1990), 233.

46 Kemp, "The Science of Art," 222.

47 Kemp, "The Science of Art," 233. 
suited to military cartography and for making engineering and architectural blueprints. This may have been the case in Early China as well. Extant texts indicate that the concept of military cartography predated the Han dynasty, and the discovery of the Mawangdui topographic and garrison maps has proven that the concept was put to practice before $168 \mathrm{BCE} .{ }^{48}$ In the Anping townscape, the painstakingly measured and meticulously executed lines reflect a high level of technical draftsmanship, leading a team of distinguished Chinese historical geographers to include the Anping townscape in their comprehensive survey on ancient Chinese cartography. ${ }^{49}$ This categorization is significant because the concept of a $t u$ (map) in Early China was ambiguous and widely inclusive. ${ }^{50}$

Although the Anping townscape is unique among known excavated examples from Early China, the concept of a mental map may not have been unique in the ancient world. Archaeological excavations have led to the discovery of a fresco in a buried gallery under Trajan's Bath. ${ }^{51}$ The fresco was found on the transverse wall of a subterranean gallery below an exedra and has been described as remarkable for its subject and size. The subject is unique in the tradition of Classical wall painting in that rural landscapes predominate, and the mural occupies almost 10 square meters, roughly similar in size to the Anping townscape. The creation of this fresco predated the reign of Trajan and was likely made during the Flavian era. ${ }^{52}$ Classical archaeologists have dubbed this fresco città dipinta (the painted city) because it shows a bird's-eye view of a walled city (Figures 2 and 3).

Buildings are represented in an axonometric perspective, among them, a theater, near which stands a statue of Apollo on a plinth; there is also a courtyard surrounded by porticoes with more statues inside. A temple is seen at the summit of a hill. In the middle of the town, there is a colossal statue painted in yellow (likely simulating bronze) at the crossing of two streets that divides the town into regular units. Scholars have debated about the identification of this "place" and, because of the complete absence of human figures in this image, many have questioned whether this town is real or imagined. I should also note that this townscape is shown in a partial view similarly to that of the Anping townscape.

48 Mei-Ling Hsu, “The Han Maps and Early Chinese Cartography,” Annals of the Association of American Geographers 68.1 (1978), 45-60.

49 Wanru Cao, et al., eds., Zhongguo gudai ditu ji: Zhanguo-Yuan (Beijing: Wenwu chubanshe, 1990).

50 Hsu, "The Han Maps and Early Chinese Cartography," 45-60.

51 Eugenio la Rocca, “The Newly Discovered City Fresco from Trajan's Baths, Rome," Imago Mundi 53 (2001), 121-4. The only other English language publication on the painting is found in Caroline Vout, The Hills of Rome: Signature of an Eternal City (Cambridge: Cambridge University Press, 2012).

52 la Rocca, “The Newly Discovered City Fresco from Trajan’s Baths, Rome,” 123. 


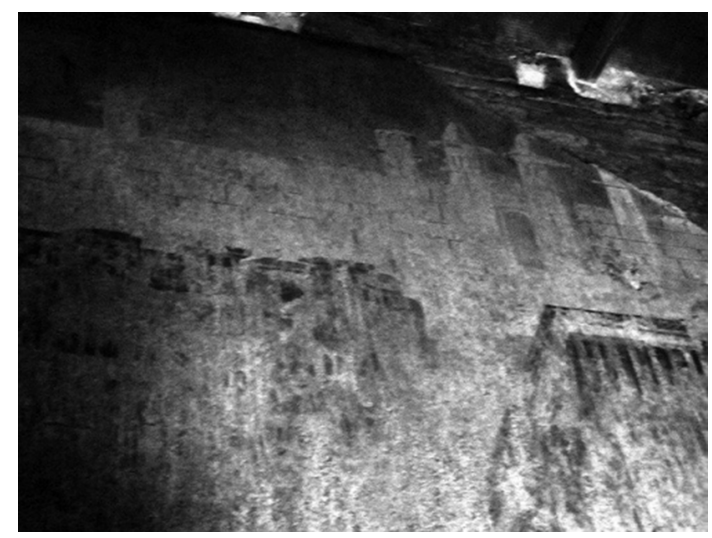

Figure 2: A detail of the Città Dipinta fresco found on the wall of a Vespasian-era structure beneath the Baths of Trajan, showing city walls, towers, a gate, houses, and public sculptures. Photo by Candace Livingston, 2005.

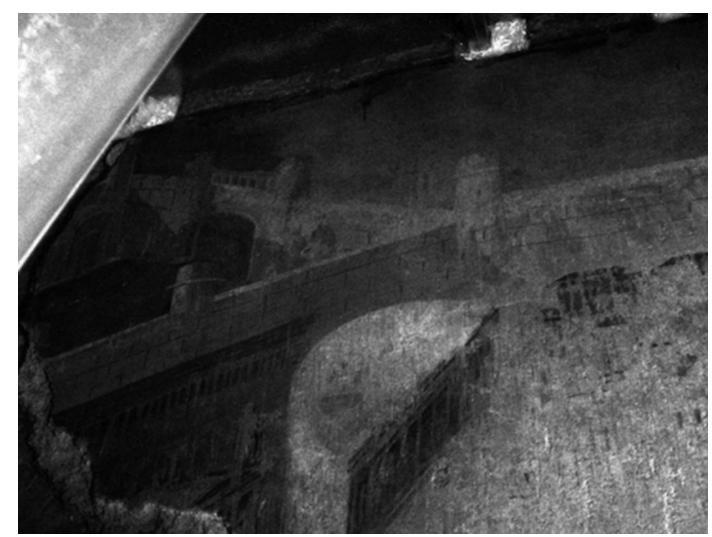

Figure 3: Another detail of the Città Dipinta fresco, showing a partial view of a port with docks and a theater. Photo by Candace Livingston, 2005.

Italian archaeologist Eugenio la Rocca wrote these words that were nearly identical to my own description of the Anping tomb around the same time. He stated: "We must be content with appreciating the fresco on the Oppian Hill as, in my view, an example of the 'chorographical genre' of painting, a style that would have been executed by a topographos, a landscape painter specializing in topographical 
maps. The purpose of the representation should thus be seen not as purely artistic and decorative, but as cartographical, descriptive and symbolic."53

My unorthodox approach to this ancient Chinese painting of a town as a chorograph from an emic perspective, based on the tomb's pictorial programming and relevant material evidence, was galvanized by previous unsatisfactory attempts to treat early depictions of space from traditional single-disciplinary perspectives. Having spent the last decade on exploring different methodologies of studying ancient cartography - first using Geographic Information System (GIS) technology to "read" the Mawangdui topographic and garrison maps, and subsequently, applying Foucauldian discourse analysis to "deconstruct" the Anping townscape - I have come to understand Heisenberg's observation on the limits of knowledge and the inherent paradox of cartography fittingly described by Christian Jacob: the map as a rational construction of an intellectual space guided by science, and “the map's power of seduction; its status as an image, its oneiric and mythic implications, the reverie it suggests to the gaze whenever the viewer's eyes slip freely over its surface. This type of representation would seem to constitute a privileged space of projection for the viewer's desires, aspirations, and affective and cultural memories."54

\section{References}

Anna, Norbert Miller, Werner Oechslin and Bernhard Schneider, eds., "Zeichnung als Medium der Abstraktion/Drawing as a Medium of Abstraction," DAIDALOS (1981)

Brown, Lloyd. The Story of Maps (Boston: Little, Brown, and Co., 1949)

Bulling, Anneliese. "The Eastern Han Tomb at Ho-lin-ko-erh (Holingol)," Archives of Asian Art 31 (1977-8), 79-103

Cao Wanru, et al., eds. Zhongguo gudai ditu ji: Zhanguo-Yuan (Beijing: Wenwu chubanshe, 1990)

Capon, Edmund. Qin Shihuang: Terracotta Warriors and Horses (Clayton, Victoria, Australia: Wilke and Company Limited, 1983)

Caswell, James 0. "Some 'Secrets of the Trade' in Chinese Painters' Use of 'Perspectives'," RES: Anthropology and Aesthetics, n. 40 (Autumn, 2001), 188-210

Downs, Roger, and Dr. David Stea, Maps in Minds: Reflections on Cognitive Mapping, Harper \& Row series in geography (New York: Joanna Cotler Books, 1977)

Faye, Jan. "Copenhagen Interpretation of Quantum Mechanics," in Edward N. Zalta, ed., The Stanford Encyclopedia of Philosophy (Stanford: Stanford University Press, 2014). https:// plato.stanford.edu/archives/fall2014/entries/qm-copenhagen/.

53 Ibid.

54 Jacob, “The Sovereign Map,” 2. 
Foucault, Michel. “Questions on Geography?” in Colin Gordon, ed. and trans., Power/ Knowledge: Selected Interviews and Other Writings, 1972-1977 (New York: Pantheon, 1980), 63-77

Graham, Elspeth. "What is a Mental Map?" The Royal Geographical Society (with the Institute of British Geographers) v. 8, n. 4 (1976), 259-262

Harley, J. B. "Deconstructing the Map," Cartographica, v. 26, n. 2 (Spring 1989), 1-20

Harley, J. B. “Maps, Knowledge, and Power," in Denis Cosgrove and Stephen Daniels, eds., The Iconography of Landscape: Essays on the Symbolic Representation, Design, and Use of Past Environment (Cambridge: Cambridge University Press, 1988), 277-311

Hebeisheng Wenwu Yanjiusuo, Anping Dong Han bihua mu (Beijing: Wenwu chuban she, 1990)

Heisenberg, Werner. Physics and Philosophy: The Revolution in Modern Science (New York: Harper and Brothers, 1958)

Hsu, Hsin-Mei Agnes and Ann Martin-Montgomery. "An Emic Perspective of the Mapmaker's Art in Han China," Journal of the Royal Asiatic Society, ser. 3, v.17, n. 4 (October, 2007), 443-457

Hsu, Hsin-Mei Agnes. "Structured Perceptions of Real and Imagined Landscapes in Early China," in Kurt A. Raaflaub and Richard J. A. Talbert, eds., Geography and Ethnography: Perceptions of the World in Pre-Modern Societies (Oxford: Wiley-Blackwell, 2010), 43-63

Hsu, Mei-Ling. "The Han Maps and Early Chinese Cartography," Annals of the Association of American Geographers 68.1 (1978), 45-60

Ianniciello, Celeste. "Postcolonial Art: A Living Archive of Border-Crossings and Migrant Matters," in Anna Maria Guasch Ferrer, Nasheli Jimenez Del Val, eds., Critical Cartography of Art and Visuality in the Global Age (Newcastle upon Tyne: Cambridge Scholars Publishing, 2014), 19-34

Jacob, Christian. The Sovereign Map: Theoretical Approaches in Cartography throughout History, Tom Conley, ed. and Edward E. Dahl, trans. (Chicago: University of Chicago Press, 2006)

Kemp, Martin. The Science of Art: Optical Themes in Western Art from Brunelleschi to Seurat (New Haven: Yale University Press, 1990)

Knapp, Ronald G. China's Vernacular Architecture: House Form and Culture (Honolulu, University of Hawaii Press, 1989)

Korzybski, Alfred. Science and Sanity: An Introduction to Non-Aristotelian Systems and General Semantics (New York: International Non-Aristotelian Library Publishing Company, 1933)

Krikke, J. “Axonometry: A Matter of Perspective," IEEE Computer Graphics and Applications (2000), 7-11

la Rocca, Eugenio. “The Newly Discovered City Fresco from Trajan's Baths, Rome," Imago Mundi 53 (2001), 121-124

Lynch, Kevin. The Image of the City (Cambridge: The MIT Press, 1960)

Mote, Frederic W. "The Transformation of Nanking, 1350-1400," in G. William Skinner, ed., The City in Late Imperial China (Stanford: Stanford University Press, 1977), 101-153

Needham, Joseph. Science and Civilization in China, IV (Cambridge: Cambridge University Press, 1971)

Neimenggu Wenwu Gongzuodui and Neimenggu Bowuguan, “Helinge'er faxian yizuo zhongyao de Dong Han bihua mu," Kaogu 1 (1974): 8-23. 
Simon, Jesse. "Chorography reconsidered: An alternative approach to the Ptolemaic definition," in Keith D. Lilley, ed., Mapping Medieval Geographies: Geographical Encounters in the Latin West and Beyond, 300-1600 (Cambridge: Cambridge University Press, 2013), 23-44.

Skinner, G. William. "Introduction: Urban Development in Imperial China," in G. William Skinner, ed., The City in Late Imperial China (Stanford: Stanford University Press, 1977), 3-31

Spiro, Audrey G. Contemplating the Ancients: Aesthetic and Social Issues in Early Chinese Portraiture (Berkeley: University of California Press, 1990)

Steinhardt, Nancy S. Chinese Imperial City Planning (Honolulu: University of Hawaii Press, 1990)

Steinhardt, Nancy S. "Representations of Chinese Walled Cities in the Pictorial and Graphic Arts," in J.D. Tracy, ed., City Walls: The Urban Enciente in Global Perspective (Cambridge: Cambridge University Press, 2000), 419-460

Wen Fong, "Why Chinese Painting is History," Art Bulletin 85.2 (2003), 258-280

Wimmel, Hermann. Quantum Physics \& Observed Reality: A Critical Interpretation of Quantum Mechanics (Singapore: World Scientific Publishing Pte. Ltd., 1992)

Xu Yinong. The Chinese City in Space and Time: The Development of Urban Form in Suzhou (Honolulu: University of Hawaii Press, 2000)

Yee, Cordell. "Reinterpreting Chinese Geographical Maps," in J.B. Harley and David Woodward, eds., The History of Cartography Project, Volume 2, Book 2 (Chicago: University of Chicago Press, 1994), 35-70

Zhou Changshan, Handai chenshi yanjiu (Beijing: Renmin chubanshe, 2001) 